\title{
COMPARISON OF BONE HEALING AROUND NANO TOPOGRAPHY DENTAL IMPLANT VERSUS CONVENTIONAL IMPLANT
}

\author{
Ali H. Amer ${ }^{l} B D S$, Saeeda M. Osman ${ }^{2} P h D$, Lydia N. Foad ${ }^{3} P h D$
}

\begin{abstract}
INTRODUCTION: Implant surface characteristics differ greatly among various Implants. Early bone healing around the implant surface can be crucial in determining various treatment plans and outcomes.

OBJECTIVES: Comparison of early bone healing between two commercially available implants one with a nanotopographical surface and one with a conventionally treated surface in the maxillary anterior region of the oral cavity using cone beam CT.

MATERIALS AND METHODS: Seven patients were selected from Department of Oral and Maxillofacial Surgery, Faculty of Dentistry, Alexandria University where patients were indicated for bilateral maxillary anterior implants as delayed Implantation with a total of 14 implants divided into two groups: Study group: Seven implants with a nanotopographic surface. Control group: Seven implants with a conventional surface. Bone density was measured according to gray scale using CBCT and dedicated software pre-operatively and at four and six weeks postoperatively.

RESULTS: For control group implants the average mean and standard deviation of bone density of the placed implants at four weeks postoperatively was $1010.02 \pm 142.59$ Hounsfield units and $1104.4 \pm 152.9 \mathrm{HU}$ at six weeks post-operatively. While for study group implants the average mean and standard deviation of bone density of the placed implants at four weeks post-operatively was $1208.04 \pm 145.82 \mathrm{HU}$ and $1328.85 \pm 160.41 \mathrm{HU}$ at six weeks post-operatively. After comparing these results, it was shown that the average mean and standard deviation of bone density of all implants of the study group is greater than the average mean and standard deviation of bone density of all implants of the control group, which results in $\mathrm{p}$-value of $<0.001$ which is statistically significant.

CONCLUSIONS: There is a significant increase in the early bone healing around nanotopographic dental implants as opposed to conventionally chemically modified implants.

KEY WORDS: Surface treatment, nanotopographic implants, chemically modified implants, early bone healing, cone beam CT, Hounsfield Units.

1- Bachelor of Dentistry,Faculty of Dentistry, Alexandria University, Alexandria, Egypt.

2- Professor of Oral and Maxillofacial Surgery, Faculty of Dentistry, Alexandria University, Alexandria, Egypt.

3- Assistant Professor of Oral and Maxillofacial Surgery, Faculty of Dentistry, Alexandria University, Alexandria, Egypt.
\end{abstract}

\section{INTRODUCTION}

Dental implant treatment modality has become a routine procedure in today's health care. High success rate and patient's acceptance has contributed to the fame of dental implant. The major contributing factor for this fame is the concept of osseointegration. This concept has been described by Brånemark, as consisting of a highly differentiated tissue making 'a direct structural and functional connection between ordered living bone and the surface of a load-carrying implant $(1,2)$.

In 1978, Dr. P. Brånemark presented a two-stage threaded titanium root-form implant; he developed and tested a system using pure titanium screws which he termed fixtures (3). These were first placed in his patients in 1965 and were the first to be well-documented implants inserted into the mandible. These implants integrated within a period of six months and remained in place for the next 40 years (4).

Osseointegration is affected by several factors such as bone quality and quantity, surgical technique, Implant morphology, a period of undisturbed healing and loading conditions (5).

Implant surface topography in particular has drawn significant attention as an important factor since it has been suggested that moderately rough implant surfaces present the strongest bone responses $(6,7)$.

One of the recognized methods to chemically modify the surface is the anodic oxidation technique. It is a method to increase the thickness of the oxide layer with a possibility to incorporate elements such as magnesium and phosphates and also provide a unique porous topography (8-11). It has been proven that this modification significantly improves both the rate and quality of osseointegration (8).

In order to further enhance osseointegration, recent research has focused on modifying the topography at the Nano level, since cells and proteins are reportedly interacting at this level $(12,13)$. It has been reported in several studies that the application of nanostructures increases the bioactivity of the implant surface which leads to an enhanced bone apposition around Implants $(14,15)$.

Although both nanotopographical and chemical modifications have proven to be an enhancing factor for osseointegration, it is of interest to observe the bone forming characteristics of commercially available implants possessing either one of the factors (16).

In this study, two commercially available implants, one possessing nanostructures formed by noble gas ion bombardment and another chemically modified implant with calcium incorporated anodic oxidation, were characterized by various methods. Thereafter, the two commercially available implants were placed in the jaw bones to observe clinically and radiographically the early bone healing at four and six weeks. 


\section{MATERIALS AND METHODS}

This study was a randomized clinical trial on seven cases selected from outpatient clinic of the Oral and Maxillofacial Surgery department, Faculty of Dentistry, Alexandria University. An appropriate ethical clearance has been obtained from the faculty and the informed consent had been signed by patients. Each case received bilateral anterior maxillary implants as delayed implantation with a total of 14 implants divided into groups:

Study Group: Seven implants consisting of titanium oxide (TiO2) micro blasted and noble gas ion bombarded surface were placed in seven patients following the delayed submerged protocol.

Control group: Seven implants of an anodic oxidized surface with calcium and phosphate incorporation were placed in seven patients following the delayed submerged protocol.

The inclusion criteria for this research were partially edentulous anterior maxilla in adults both males and females with an age ranging from 20-50 years, sufficient bone volume, good oral hygiene and non- smokers. The exclusion criteria were active infection (periodontitis or mucosal infection), current chemotherapy or radiotherapy, indication for bone graft in the implant site, alcohol or drug abuse, pregnancy and uncontrolled systemic diseases (Diabetic, Autoimmune diseases, etc).

\section{The implant system}

Fourteen P-I (Professor Per-Ingvar Brånemark) Amplified Functional Hybrid Implants with available diameters of $(3.3,4,4.8) \mathrm{mm}$ and available lengths of $(7,8.5,10,11.5$, 13, 15) mm (Zimmer Biomet, Poland).

Implants placed were divided equally between cases where each case received one implant with an OSPOL surface (anodic oxidized surface with calcium and phosphate incorporation, Zimmer Biomet, Poland) and one implant with a MICRO+NANO surface (titanium oxide (TiO2) micro blasted and noble gas ion bombarded surface, Zimmer Biomet, Poland). Figure (1).

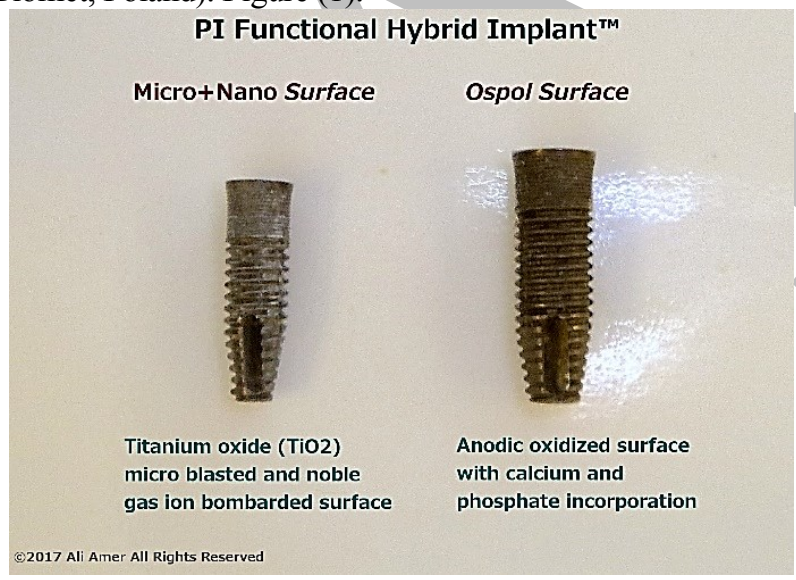

Figure 1: Photograph showing the P-I Functional Hybrid implant with the two surface treatments.

\section{Methods:}

\section{A. Preoperative phase \\ Clinical examination}

Patient's data were collected; name, gender and age, medical and dental history was taken. Clinical examination was performed, the oral mucosa of the edentulous area was examined for color, texture, firmness and thickness, the edentulous area of the operative site was examined for undercuts by palpation through the soft tissue.

\section{Radiographic examination}

All patients underwent pre-operative radiographic examination using Cone beam computed tomography (CBCT) to measure the available bone, selection of the right size implant for optimal support, precision placement of implants in the bone, their relation to adjacent structures and to evaluate the condition of bone. (Figure 2a), (Figure 3a).

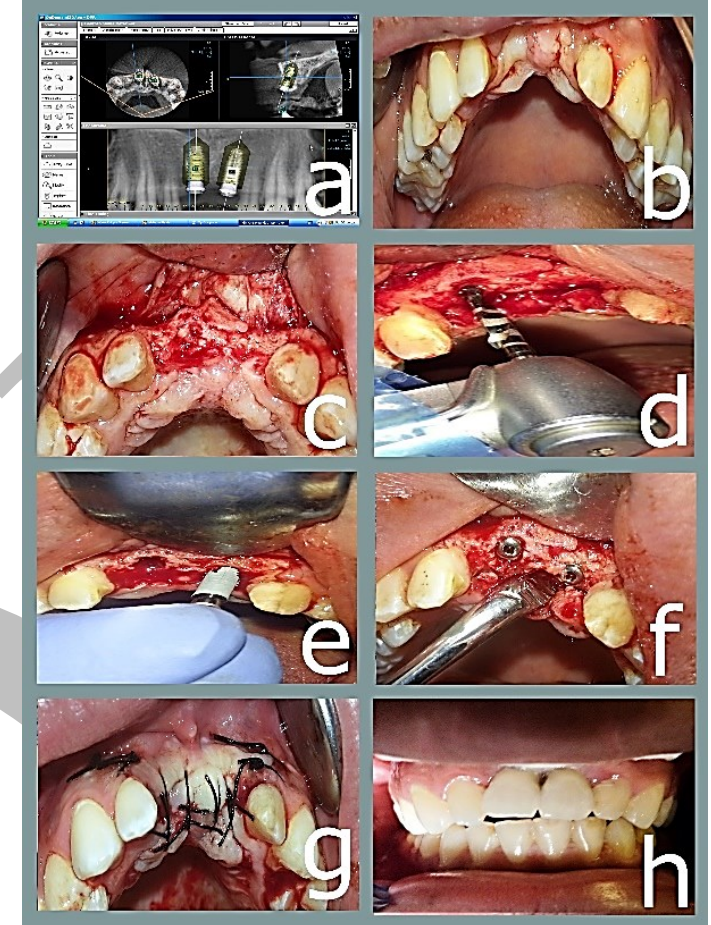

Figure 2: Photograph showing case number 1

a. Photograph showing cone beam CT Implant placement plan.

b. Photograph showing Incision of the mucoperiosteum.

c. Photograph showing reflection of a full mucoperiosteum.

d. Photograph showing sequential drilling.

e. Photograph showing implants placement (control group-Ospol surface and study group-Micro+Nano surface).

f. Photograph showing cover screws placement.

g. Photograph showing repositioning and suturing mucoperiosteal flap.

h. Photograph showing final porcelain fused to metal fixed prosthesis.

\section{B. Surgical phase}

Preoperative oral antibiotics one hour before surgery was given in the form of Amoxicillin $875 \mathrm{mg} /$ clavulanic acid $125 \mathrm{mg}$ (Augmentin1gm: GSK GlaxoSmitheKline, England) and $0.12 \%$ chlorhexidine (Hexitol: The Arab drug CO, Egypt) mouth wash was used to rinse for 30 seconds before operation.

The surgery began with the patient under local anaesthesia (Articaine HCL with epinephrine 1:100,000) (Ubistesin forte: 3M ESPE, Germany).

Full mucoperiosteal flap was raised exposing the alveolar bone at the site of implant placement. The osteotomy was carried out in the central part of the alveolar bone where the initial drilling of the implant site was done with a pilot drill of $2.2 \mathrm{~mm}$ (800 RPM) under copious sterile saline irrigation according to the implant length pre-measured from the CBCT. A parallel pin was placed in the osteotomy site to confirm the position and the angulation of the osteotomy, the osteotomy was then widened using an intermediate drill (800 RPM) and the final drill (800 RPM) according to the diameter of the implant. The implant was then threaded into the bone using a ratchet wrench with an insertion 
torque between 25 and $50 \mathrm{Ncm}$. The cover screw was then placed in place with the screw driver. The mucoperiosteal flap was repositioned and sutured following the submerged implant placement protocol. (Figure $2 \mathrm{~b}-\mathrm{g}$ ), (Figure $3 \mathrm{~b}-\mathrm{g}$ ), (Figure $4 \mathrm{a}-\mathrm{g}$ ).

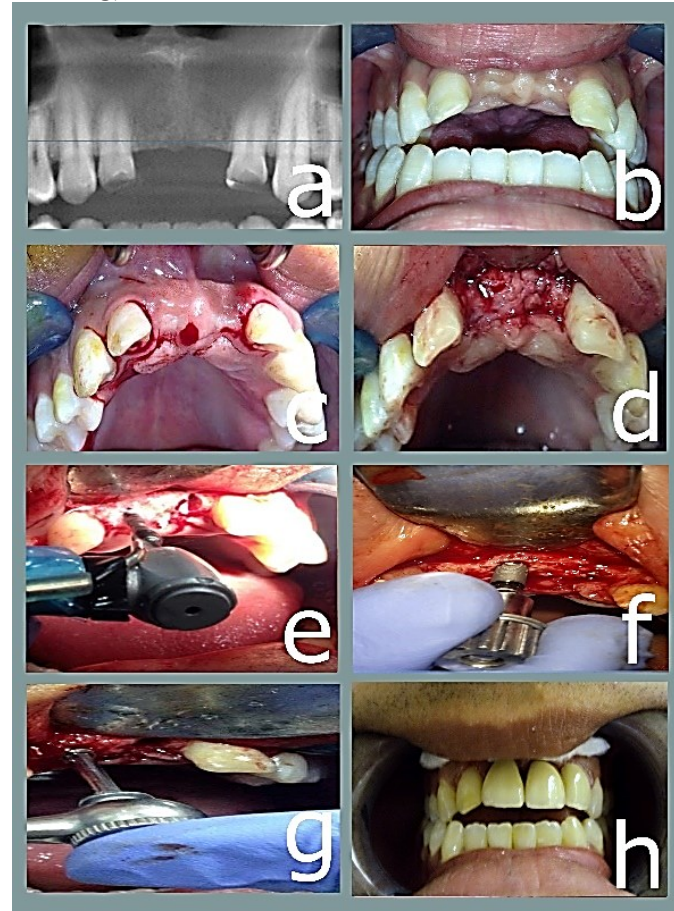

Figure 3: Photograph showing case number 2.

a. Photograph showing pre-operative $\mathrm{x}$-ray.

b. Photograph showing pre-operative maxillary arch.

c. Photograph showing Incision of the mucoperiosteum.

d. Photograph showing reflection of a full mucoperiosteum.

e. Photograph showing sequential drilling.

f. Photograph showing implant placement (control group-Ospol surface).

g. Photograph showing securing implant in place using torque wrench.

h. Photograph showing final porcelain fused to metal fixed prosthesis.

\section{Postoperative phase}

\section{Postoperative instructions}

All patients were advised to apply cold packs extra orally intermittently every ten minutes for two hours on the first day, chlorohexidine mouth (Hexitol: The Arab drug CO. Cairo, a.R) wash was started on the second post-operative day three times daily for two weeks, the sutures were removed after one week post surgically. Antibiotic Amoxicillin (875) / clavulanic acids (125) 1gm tab (Augmentin: GSK GlaxoSmitheKline, England) every 12 hours daily for five days, non-steroidal anti-inflammatory drugs ibuprofen 400mg (Ibuprofen: EIPICO, Egypt), every eight hours daily for three days were given.

\section{Postoperative follow-up}

\section{Clinically}

All patients were examined clinically for:

\section{i.Pain}

Pain was evaluated using Visual Analogue Scale (VAS) (17) on the second and seventh post-operative days. It's a horizontal line, $100 \mathrm{~mm}$ in length, anchored by word descriptors at each end. The patients mark on the line the point that they feel represents their perception of their current state. The VAS score is determined by measuring in millimeters from the left hand end of the line to the point that the patients mark. Tenderness and discomfort were evaluated according to the signs and symptoms of the patients.

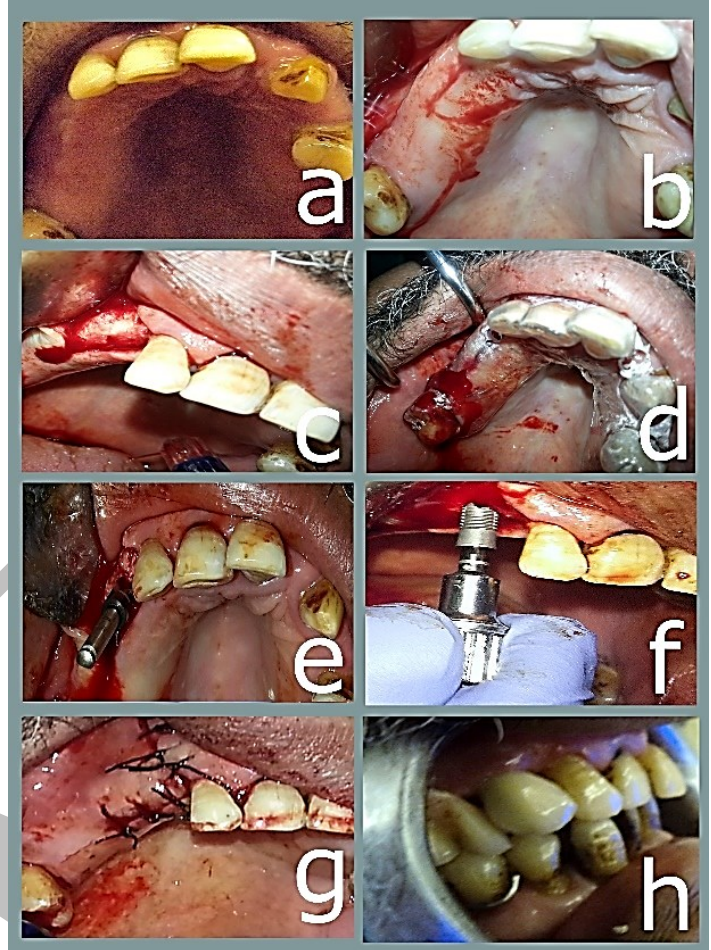

Figure 4: Photograph showing case number 3 restored right maxillary cuspid.

a. Photograph showing pre-operative maxillary arch.

b. Photograph showing Incision of the mucoperiosteum.

c. Photograph showing reflection of a full mucoperiosteum.

d. Photograph showing silicone vacuum formed surgical stent.

e. Photograph showing checking parallelism.

f. Photograph showing implant placement (control group-Ospol surface).

g. Photograph showing repositioning and suturing mucoperiosteal flap.

h. Photograph showing final porcelain fused to metal fixed prosthesis.

\section{ii.Mobility of the implant}

Mobility was tested at four months postoperatively upon exposure of the implants and abutments insertion according to McKinney and Koth (18) (during the post-operative follow up phase) using back and forth pressure by two instrument handles.

Implant mobility indicates lack of osseointegration. Therefore, mobility was used as a specific diagnostic test pointing to loss of osseointegration and being decisive in making the decision to remove the affected implant.

The clinical implant mobility scale is:

Scale 0: Absence of clinical mobility in any direction.

Scale 1: Slight detectable horizontal movement.

Scale 2: Moderate visible horizontal mobility up to $0.5 \mathrm{~mm}$. Scale 3: Severe horizontal movement greater than $0.5 \mathrm{~mm}$. Scale 4: Visible moderate to severe horizontal movement and any visible vertical movement.

\section{iii.Gingival index}

Evaluation of gingival condition around the implant for presence of any inflammation. This was assessed using the Löe and Silness Gingival Index (19) at four months postoperatively. The category criteria for assessment were as follows:

0 Normal gingival. 
1 Mild inflammation, slight change in color, slight edema, no bleeding on probing.

2 Moderate inflammation, redness, edema and glazing, bleeding on probing.

3 Severe inflammation, marked redness and edema, ulcerations, tendency to spontaneous bleeding.

\section{Radiographically}

All patients were evaluated radiographically immediately post-operatively by orthopantogramic radiographs. Patients were examined on intervals of four \& six weeks postoperatively by CBCT.

\section{CBCT specifications}

Exposure was performed using (veraviewepocs 3D R100, J. Morita, Japan) at $8 \mathrm{~mA}, 90 \mathrm{KV}$ and at a proper field of view.

Image reconstruction was performed using special software (OnDemand3D version 1.0.9, Cybermed, Korea). Standardization during imaging was achieved through adjusting the patient positioning and lights as follows:

1. The seat height was adjusted to position the region of interest (ROI) vertically within the field of view (FOV).

2. The upper light beam indicated the top of the FOV and the lower light beam indicated the bottom of the beam.

3. The sagittal light (vertical front light) was positioned in the center of the FOV from a sagittal direction so that it is in the center of the ROI.

4. The lateral light (vertical side light) was positioned in the center of the FOV on the lateral direction so that it is in the center of the ROI.

5. The patient was instructed not to move during the duration of the exposure.

\section{Prosthetic phase}

The final prosthesis (porcelain fused to metal crown) was placed after four months. (Figures 2h, 3h, 4h).

\section{STATISTICAL ANALYSIS}

Data were fed to the computer and analyzed using IBM SPSS software package version 20.0. (Armonk, NY: IBM Corp) (20, 21). Qualitative data were described using number and percent. The Kolmogorov-Smirnov test was used to verify the normality of distribution. Quantitative data were described using range (minimum and maximum), mean, standard deviation and median.

Significance of the obtained results was judged at the 5\% level.

The used tests were

1 - Paired t-test

For normally quantitative variables, to compare between two periods

2 - ANOVA with repeated measures

For normally quantitative variables, to compare between more than two periods or stages, and Post Hoc test (LSD) (Bonferroni adjusted) for pairwise comparisons.

3 - Wilcoxon signed ranks.

\section{RESULTS}

The present study was conducted on seven cases requiring two implants placement in the anterior region of maxilla. (four females and three males) selected from the outpatient clinic of the Oral and Maxillofacial Surgery Department, Faculty of Dentistry, Alexandria University. Their ages ranged between 20 and 50 years with mean age of 33 years. All the teeth replaced in this study were single rooted maxillary teeth where cases were five cases with two missing maxillary central incisors, one case with missing left maxillary lateral incisor and missing right maxillary cuspid, one case with missing cuspids bilaterally.

Implants used in this research were seven implants (3.3mm diameter \& $11.5 \mathrm{~mm}$ length implants), five implants (3.3mm diameter \& $10 \mathrm{~mm}$ length implant), one implant (4mm diameter \& $10 \mathrm{~mm}$ length implant) and one implant (4mm diameter \& $13 \mathrm{~mm}$ length implant).

All patients were followed up both clinically and radiographically for six months. Final restorations for all cases were performed after four months from implant placement.

All patients had been examined periodically during the follow-up period up to six months. All patients had completed the scheduled follow up.

Healing was uneventful in all cases with no postoperative complications. Other clinical parameters had been recorded during the follow up period such as: Pain index, gingival index and implant mobility.

\section{1) Pain}

After surgery, all patients experienced mild to moderate pain at the surgical site. Five patients experienced moderate pain which subsided on the third postoperative day while two patients experienced mild pain which vanished on the second postoperative day.

\section{2) Gingival Index}

No signs of gingival inflammation were observed in all patients all over evaluation period. (i.e. gingival index score was zero).

\section{3) Implant mobility}

All over the evaluation period, none of the implants showed any signs of mobility. (i.e. mobility score was zero).

\section{Radiographic evaluation}

Using Cone beam CT before Implant placement and four weeks and six weeks after implant placement to evaluate:

Bone Density Measurement in Hounsfield Units for each implant group before and after four and six weeks postoperatively using dedicated software; (OnDemand3D Software, Korea). (Tables 1,2 \& 3).

\section{For the control group}

Data were collected for study group and control group regarding mean peri-implant bone density values and standard deviation at four weeks' post-operative and at six weeks.

On the first four weeks post-operatively, the mean periimplant bone density value for the control group (Ospol) was $1010.02 \pm 142.59 \mathrm{HU}$ with a minimum recorded value of $884.45 \mathrm{HU}$ and a maximum recorded value of 1277.18 $\mathrm{HU}$, with a mean percentage of difference from baseline value that equals $10.04 \pm 3.46 \%$. (Table 1 ).

On the sixth week, the mean peri-implant bone density value for the control group (Ospol) was 1104.4 $\pm 152.9 \mathrm{HU}$ with a minimum recorded value of $972.89 \mathrm{HU}$ and a maximum recorded value of $1405.04 \mathrm{HU}$, with a mean percentage of difference from baseline value that equals $20.41 \pm 5.15 \%$. (Table 1 ).

\section{For the study group}

On the first four weeks post-operatively, the mean periimplant bone density value for the study group (Micro+Nano) was 1208.04 $\pm 145.82 \mathrm{HU}$ with a minimum recorded value of $998.22 \mathrm{HU}$ and a maximum recorded value of $1474.85 \mathrm{HU}$, with a mean percentage of difference from baseline value that equals $39.39 \pm 13.13 \%$. (Table 2 ).

On the sixth week, the mean peri-implant bone density value for the study group (Micro+Nano) was $1328.85 \pm$ 
160.41 HU with a minimum recorded value of 1098.1 HU and a maximum recorded value of $1622.4 \mathrm{HU}$, with a mean percentage of difference from baseline value that equals $53.34 \pm 14.43 \%$. (Table 2).

Table 1: Distribution of the studied cases according to bone density (HU) control group (Ospol) $(n=7)$.

\begin{tabular}{|l|c|c|c|c|c|}
\hline \multirow{2}{*}{ Ospol } & \multirow{2}{*}{ Pre } & \multicolumn{2}{|c|}{ Post } & \multirow{2}{*}{ F } & \multirow{2}{*}{ p } \\
\cline { 3 - 4 } & & 4 Weeks & 6 Weeks & & \\
\hline Min. - & $781.69-$ & $884.45-$ & $972.89-$ & & \\
Max. & 1161.3 & 1277.18 & 1405.04 & & \\
Mean \pm & $920.54 \pm$ & $1010.02 \pm$ & $1104.4 \pm$ & & \\
SD. & 146.8 & 142.59 & 152.9 & $132.68^{*}$ & $<0.001^{*}$ \\
Median & 842.15 & 934.27 & 1027.71 & & \\
\hline Difference & & $89.47 \pm$ & $183.85 \pm$ & & \\
\cline { 1 - 3 } \% of & & 25.65 & 40.53 & & \\
\cline { 3 - 4 } difference & & $10.04 \pm$ & $20.41 \pm$ & & \\
\cline { 1 - 3 } $\begin{array}{l}\text { Sig. bet. } \\
\text { periods }\end{array}$ & \multirow{2}{*}{$\mathrm{p}_{1}<0.001^{*}, \mathrm{p}_{2}<0.001^{*}, \mathrm{p}_{3}<0.001^{*}$} & & \\
\hline
\end{tabular}

F, p: F, p value for $\mathbf{F}$ test (ANOVA) with repeated measures for comparing between different periods

$\mathrm{p}_{1}$ : $\mathrm{p}$ value for comparing between pre and post 4 weeks $p_{2}$ : $p$ value for comparing between pre and post 6 weeks $\mathrm{p}_{3}$ : $\mathrm{p}$ value for comparing between 4 weeks and post 6 weeks. *: Statistically significant at $\mathrm{p} \leq 0.05$

After comparing the above results of bone density values of the two groups it was shown that the average mean and standard deviation of bone density of all implants of the study group (micro+nano) was greater than the average mean and standard deviation of bone density of all implants of the control group (ospol), which resulted in a p-value of the study of $<0.001$ at four and six weeks which is statistically significant as shown in the table. (Table 3, Fig. $5)$.

Table 2: Distribution of the studied cases according to bone density (HU) study group (Micro+Nano) $(n=7)$.

\begin{tabular}{|c|c|c|c|c|c|}
\hline \multirow{2}{*}{$\begin{array}{c}\text { Micro } \\
\text { Nano }\end{array}$} & \multirow{2}{*}{ Pre } & \multicolumn{2}{|c|}{ Post } & \multirow{2}{*}{$\mathbf{F}$} & \multirow{2}{*}{$\mathbf{p}$} \\
\hline & & 4 Weeks & 6 Weeks & & \\
\hline $\begin{array}{l}\text { Min. - } \\
\text { Max. }\end{array}$ & $\begin{array}{l}670.51- \\
1129.92\end{array}$ & $\begin{array}{l}998.22- \\
1474.85\end{array}$ & $\begin{array}{l}1098.1- \\
1622.4\end{array}$ & \multirow{3}{*}{$267.03^{*}$} & \multirow{3}{*}{$<0.001^{*}$} \\
\hline $\begin{array}{l}\text { Mean } \pm \\
\text { SD. }\end{array}$ & $\begin{array}{c}879.27 \pm \\
175.20\end{array}$ & $\begin{array}{r}1208.04 \\
\pm 145.82\end{array}$ & $\begin{array}{c}1328.85 \pm \\
160.41\end{array}$ & & \\
\hline Median & 840.24 & 1203.47 & 1323.83 & & \\
\hline Difference & & $\begin{array}{c}328.77 \pm \\
74.02\end{array}$ & $\begin{array}{c}449.61 \pm \\
72.80\end{array}$ & & \\
\hline $\begin{array}{l}\text { \% of } \\
\text { difference }\end{array}$ & & $\begin{array}{c}39.39 \pm \\
13.13\end{array}$ & $\begin{array}{c}53.34 \pm \\
14.43\end{array}$ & & \\
\hline $\begin{array}{l}\text { Sig. bet. } \\
\text { periods }\end{array}$ & \multicolumn{3}{|c|}{$\begin{array}{c}\mathrm{p}_{1}<0.001^{*}, \mathrm{p}_{2}<0.001^{*}, \mathrm{p}_{3} \\
<0.001^{*}\end{array}$} & & \\
\hline
\end{tabular}

$\mathrm{F}, \mathrm{p}: \mathrm{F}, \mathrm{p}$ value for $\mathbf{F}$ test (ANOVA) with repeated measures for comparing between different periods

$\mathrm{p}_{1}$ : $\mathrm{p}$ value for comparing between pre and post 4 weeks $\mathrm{p}_{2}$ : $\mathrm{p}$ value for comparing between pre and post 6 weeks p3: $p$ value for comparing between 4 weeks and post 6 weeks

*: Statistically significant at $\mathrm{p} \leq 0.05$

\section{DISCUSSION}

The high success rate of titanium dental implants has been attributed to formation of a direct bone-implant interface with no intervening soft tissues (22). However, treatment of jaws with advanced resorption and poor bone quality presents a high rate of implant failure. One way to decrease this clinical problem is to use a dental implant with a treated surface. It has been suggested that physiochemical and dielectric properties, crystal structure and surface morphology of titanium oxide films on dental implant surfaces play a crucial role in the biocompatibility and osseointegration of implants (23-25).

Table 3: Comparison of the studied cases according to bone density (HU) control group (Ospol) and study group (Micro+Nano).

\begin{tabular}{|c|c|c|c|}
\hline & \multirow{2}{*}{ Pre } & \multicolumn{2}{|c|}{ Post } \\
\hline & & 4 Weeks & 6 Weeks \\
\hline Ospol & & & \\
\hline $\begin{array}{l}\text { Min. - } \\
\text { Max. }\end{array}$ & $781.69-1161.3$ & $884.45-1277.18$ & $972.89-1405.04$ \\
\hline $\begin{array}{l}\text { Mean } \pm \\
\text { SD }\end{array}$ & $920.54 \pm 146.8$ & $1010.02 \pm 142.59$ & $1104.4 \pm 152.9$ \\
\hline Median & 842.15 & 934.27 & 1027.71 \\
\hline $\begin{array}{l}\text { Micro } \\
\text { Nano }\end{array}$ & & & \\
\hline $\begin{array}{l}\text { Min. - } \\
\text { Max. }\end{array}$ & $\begin{array}{l}670.51- \\
1129.92\end{array}$ & $998.22-1474.85$ & $1098.1-1622.4$ \\
\hline $\begin{array}{l}\text { Mean } \pm \\
\text { SD. }\end{array}$ & $879.27 \pm 175.20$ & $1208.04 \pm 145.82$ & $1328.85 \pm 160.41$ \\
\hline Median & 840.24 & 1203.47 & 1323.83 \\
\hline$p$ & 0.236 & $<0.001^{*}$ & $<0.001^{*}$ \\
\hline
\end{tabular}

$\mathrm{p}$ : $\mathrm{p}$ values for Paired t-test for comparing between control group (Ospol) and study group $(\mathrm{M}+\mathrm{N})$

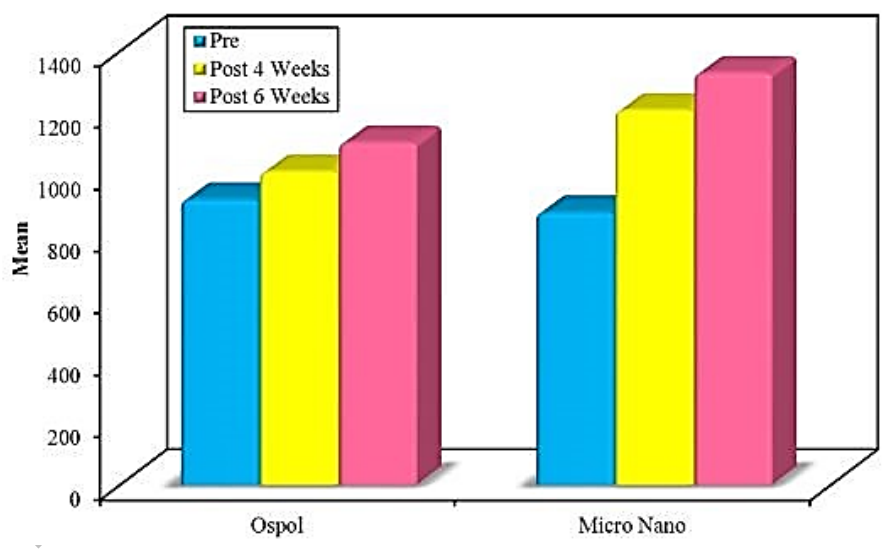

Figure 5: Photograph showing the comparison between the studied cases according to bone density (HU) control group (Ospol) and study group (Micro+Nano) $(\mathrm{n}=7)$.

This study compared early bone healing around two commercially available implants one with a nanotopographic surface and one with a conventional surface where seven adult patients (four males and three females) were selected from the outpatient clinic of the Oral and Maxillofacial Surgery Department, Faculty of Dentistry, Alexandria University. Each patient indicated for bilateral anterior maxillary implants. Their ages ranged between 20 and 50 years with a mean age of $33 \pm$ 11.2 years.

The selected patients were free from any uncontrolled systemic diseases or conditions that may complicate the surgical procedure or the healing process of the implant. This was following a study performed by Bornstein et. al. in 2009 (26), where they reviewed whether systemic diseases with/without systemic medications increased the risk of implant failure and therefore diminish the success and survival rates of dental implants. They stated that the level of evidence indicative of absolute and relative 
contraindications for implant therapy due to systemic diseases is low.

Also, patients suffering from bruxism, heavy smokers, patients receiving chemotherapy or radiotherapy and immunosuppressed patients were excluded from this study. This was following a study performed by Gomez de Diego et al in 2014 (27), where they reviewed the current scientific literature in order to analyze the indications and contraindications of dental implants in medically compromised patients and they concluded that tobacco addiction and head and neck radiotherapy are correlated to a higher loss of dental implants.

In the current study strict oral hygiene was followed by all patients during the preoperative and postoperative follow up. A number of reports of dental implants procedures have highlighted the value of maintaining strict oral hygiene measurements and using antibiotics preoperatively. Postoperative drugs including antibiotics, mouthwashes, analgesics and anti-inflammatory were prescribed for all patients. Implant placement procedures run a risk of introducing new bacteria, requiring the use of prophylactic antibiotics to prevent the infection. The antibiotic administration has been demonstrated not only to minimize the incidence of postoperative infection but also to significantly reduce the rate of implant failure (28).

In this study, patients experienced mild to moderate pain and discomfort at the surgical site which disappeared completely after the $2^{\text {nd }}$ and $3^{\text {rd }}$ post-operative days. These findings are in agreement with Al-Khabbaz et al. in 2007 (29) where they followed up pain intensity in 510 implants which were placed in 234 patients and they concluded that pain experienced by patients following the surgical placement of dental implants was generally mild and gradually decreased with time. Operator experience, female gender, surgical difficulty, and pain at earlier time-points were associated significantly with patient reports of pain.

Primary implant stability is mainly attributed to the surgical technique and implant taper. In the present study the delayed implant placement protocol was used where a low speed high torque hand piece was used for the preparation of the implant bed, and the drilling was performed under profuse irrigation using cold sterile saline for proper cooling and to avoid overheating of the bone tissues which would compromise osseointegration in accordance to Strbac et al in 2014 (30). No clinical mobility was detected in any of the implants throughout the follow up period. This was confirmed by radiographic evaluation that revealed intimate bone implant contact and absence of peri-implant radiolucency. This indicates proper osseointegration of all implants. That was in agreement with Porter and Von Fraunhofer in 2005 (31) where they conducted an extensive literature search for articles relating to dental implant failure and reported that successful implants showed no clinical mobility.

Regarding the mean peri-implant probing depth, in the present study the difference between the control group (Ospol) and the study group (Micro+Nano) was found to be statistically insignificant ( $\mathrm{p}$-value $=0.167$ ). There was no increase in the probing depth levels in all implants which indicates periodontally successful implants that was in agreement with Salvi and Lang in 2004 (32) where they conducted a review of the literature on clinical, radiographic, and biochemical parameters used for monitoring peri-implant conditions and concluded that systematic and continuous monitoring of peri-implant tissues during maintenance care is recommended for the early diagnosis of peri-implant disease.

In the present study the bone density was evaluated from CBCT radiographs. The bone density preoperatively was the lowest value during the follow up. This could be explained by the absence of functional dynamic alveolar bone stimulation due to the long standing effect of missing anterior teeth, this is in agreement with Katranji et al. in 2007 (33) who studied the cortical bone thickness in 28 dentate and edentulous human cadavers and concluded that the average cortical thickness of the buccal plates ranged from 1.0 to $2.1 \mathrm{~mm}$ in the edentulous maxilla and mandible, with the thinnest area in the anterior maxilla and the thickest area in the posterior mandible. Whereas the buccal plate of the dentate maxilla and mandible ranged from 1.6 to $2.2 \mathrm{~mm}$ in thickness, with the thinnest area in the mandibular anterior region and the thickest area in the maxillary posterior region.

The bone quality in the selected patients ranged between the D2 and D3. This was in agreement with Misch (34) who classified bone density to D1-D4; whereas the bone in the anterior maxilla was classified as D2 (750-1250 HU) or D3 (375-750 HU).

In the subsequent follow up periods the bone density around the implants increased, this was due to the compression of bone produced by the implant placement technique. The bone density increased around implants at four and six weeks postoperatively as opposed to bone density measured preoperatively. That was explained by the early healing of bone around the implants and the early osseointegration of dental implants.

The difference in bone density values between control group (Ospol surface treated Implants) and study group (Micro+Nano surface treated implants) was found to be statistically significant ( $p$-value $=0.001$ ) on the first four weeks as opposed to bone density values measured preoperatively.

After six weeks, the difference in bone density values opposed to values measured preoperatively between control group (Ospol surface treated Implants) and study group (Micro+Nano surface treated implants) was found to be satistically significant ( $\mathrm{p}$-value $=0.001)$.

The higher values of peri-implant bone density in the study group (Micro+Nano surface treated Implants) at four and six weeks postoperatively as opposed to bone density values measured preoperatively indicates a significant effect of the nanotopographical surface treated implants on the early stages of osseointegration.

These findings are in agreement with Meirelles et al. in 2008 (35) who investigated the effect of chemically modified implants with similar microtopographies but different nanotopographies on early stages of osseointegration. The implant surface modifications investigated in their study were: 1. blasting with $\mathrm{TiO} 2$ and further, 2. fluoride treatment, or 3. modification with nanohydroxy apatite. In their study 40 screw-shaped implants were placed in 10 New Zealand white rabbits and they concluded that chemical modifications used in their study were capable of producing a particular nanotopography, and together with the ions present at the implant surface, might have explained the increased removal torque values after a healing period of 4 weeks. 
Also Kim et al. in 2010 (36) who studied three implants surfaces: 1. machined surface, 2. sand blasted and acid etched surface, and 3. anodic oxidized surface. They reported that implant design and surface treatment may have significant effects on biological stability 3 weeks after implant placement.

Moreover, Ballo et al. in 2011 (37) studied an implantable model system to investigate the effects of nanoscale surface properties on the osseointegration of titanium implants in rat tibia. They emphasized the current results and findings where they concluded that after insertion in bone, a significant enhancement in bone formation was detected on Ti implant surfaces modified by 60 nanometers (semi-spheres) after 28 days of healing (four weeks).

Regarding marginal bone loss which was evident on the radiographs and settled at the implant crestal module at the end of the 6 months for both groups, which is consistent with Nandal et al. in 2014 (38) who evaluated the marginal bone level changes around dental implants based on the radiological examination. They concluded that there were no statistically significant differences between the marginal bone loss on mesial compared with the distal aspect of implant after 6 months of implant placement. Thus, the bone loss on mesial and distal aspects of implants was found to be same after a period of 6 months

Regarding the insertion torque at the time of implants placement, the difference between the control group (Ospol) and the study group (Micro+Nano) was found to be statistically insignificant (p-value $=0.110)$. That was in agreement with O'Sullivan et al. in 2000 (39) who compared the primary stability of five types of endosseous dental implant of varying geometry and surface topography. They reported that all of the implants tested demonstrated good primary stability in type 2 and 3 bone.

\section{CONCLUSIONS}

Nanotopographic technology applied to the surfaces of new emerging implants have a significant enhancing effect on the early stages of bone healing and osseointegration which is a pretext for studying bone response to nanotopography with immediate implantation with/without immediate loading.

Future studies including more patients and longer follow up periods are needed to assess the long term success rate of osseointegrated nanotopographical Implants.

\section{CONFLICT OF INTREST}

The authors declare that they have no conflicts of interest.

\section{REFERENCES}

1. Brånemark PI. Vital microscopy of bone marrow in rabbit. Scand J Clin Lab Invest. 1959;11 (38):1-82. Quoted from: Uezono M, Takakuda K, Kikuchi M, Suzuki S, Moriyama $\mathrm{K}$. Hydroxyapatite/collagen nanocomposite coated titanium rod for achieving rapid osseointegration onto bone surface. J Biomed Mater Res B Appl Biomater. 2013; 101:1031-8.

2. Brånemark PI. Osseointegration and its experimental studies. J Prosthet Dent. 1983; 50:399-410.

3. Adell R, Eriksson B, Lekholm U, Branemark PI, Jemt T. Long-term follow-up study of osseointegrated implants in the treatment of totally edentulous jaws. Int $\mathrm{J}$ Oral Maxillofac Implants. 1990; 5:347-59.
4. Brånemark PI, Hansson BO, Adell R, Breine U, Lindström J, Hallén $\mathrm{O}$, et al. Osseointegrated implants in the treatment of the edentulous jaw: Experience from a 10-year period. Scand J Plast Reconstr Surg 1977; 16: 1-132. Quoted from: Chen ST, Buser D. Esthetic outcomes following immediate and early implant placement in the anterior maxilla — a systematic review. Int J Oral Maxillofac Implants. 2014; 29: 186-215.

5. Baier RE, Meyer AE. Implant surface preparation. Int J Oral Maxillofac Implants. 1988;3:9-20

6. Wennerberg A, Albrektsson T, Andersson B, Krol JJ. A histomorphometric and removal torque study of screwshaped titanium implants with three different surface topographies. Clin Oral Implants Res. 1995; 6:24-30.

7. Wennerberg A, Albrektsson T, Andersson B. Bone tissue response to commercially pure titanium implants blasted with fine and coarse particles of aluminum oxide. Int J Oral Maxillofac Implants. 1996; 11:38-45.

8. Sul YT, Byon ES, Jeong Y. Biomechanical measurements of calcium-incorporated oxidized implants in rabbitbone: effect of calcium surface chemistry of a novel implant. Clin Implant Dent Relat Res. 2004; 6:101-10.

9. Sul YT, Johansson C, Wennerberg A, Cho LR, Chang BS, Albrektsson T. Optimum surface properties of oxidized implants for reinforcement of osseointegration: surface chemistry, oxide thickness, porosity, roughness, and crystal structure. Int J Oral Maxillofac Implants. 2005; 20:349-59.

10. Sul YT, Jönsson J, Yoon GS, Johansson C. Resonance frequency measurements in vivo and related surface properties of magnesium-incorporated, micropatterned and magnesium incorporated TiUnite, Osseotite, SLA and TiOblast implants. Clin Oral Implants Res. 2009; 20:114655.

11. Sul YT, Johansson CB, Jeong Y, Röser K, Wennerberg A, Albrektsson T. Oxidized implants and their influence on the bone response. J Mater Sci Mater Med. 2001; 12:1025-31.

12. Ferreira L, Karp JM, Nobre L, Langer R. New opportunities: the use of nanotechnologies to manipulate and track stem cells. Cell Stem Cell. 2008; 3:136-46.

13. Webster TJ, Ejiofor JU. Increased osteoblast adhesion on nanophase metals: Ti, Ti6Al4V, and CoCrMo. Biomaterials. 2004; 25:4731-9.

14. Dohan DM, Coelho PG, Kang BS, Sul YT, Albrektsson T. Classifiation of osseointegrated implant surfaces: materials, chemistry and topography. Trends Biotechnol. 2010; 28:198-206.

15. Jimbo R, Sotres J, Johansson C, Breding K, Currie F, Wennerberg A. The biological response to three different nanostructures applied on smooth implant surfaces. Clin Oral Implants Res. 2012; 23:706-12.

16. Bjursten LM, Rasmusson L, Oh S, Smith GC, Brammer KS, Jin S. Titanium dioxide nanotubes enhance bone bonding in vivo. J Biomed Mater Res A. 2010; 92:1218-24.

17. Bijur PE, Silver W, Gallagher EJ. Reliability of the visual analog scale for measurement of acute pain. Acad Emerg Med. 2001; 8:1153-7.

18. Karthik K, Sivakumar, Sivaraj, Thangaswamy V. Evaluation of implant success: A review of past and present concepts. J Pharm Bioall Sci. 2013; 5(S1): 117-9.

19. Boonstra AM, SchiphorstPreuper HR, Reneman MF, Posthumus JB, Stewart RE. Reliability and validity of the visual analogue scale for disability in patients with chronic musculoskeletal pain. Int J Rehabil Res. 2008; 31:165-9. 
20. Kotz S, Balakrishnan N, Read CB, Vidakovic B. Encyclopedia of statistical sciences. Hoboken, N.J.: WileyInterscience. Vol. 2, 2nd ed. 2006: 981-89.

21. Kirkpatrick LA, Feeney BC. A simple guide to IBM SPSS statistics for version 20.0. Student ed. Belmont, Calif.: Wadsworth, Cengage Learning; 2013.

22. Adell R, Eriksson B, Lekholm U, Branemark PI, Jemt T. Long-term follow-up study of osseointegrated implants in the treatment of totally edentulous jaws. Int $\mathrm{J}$ Oral Maxillofac Implants. 1990;5:347-59.

23. Bowers KT, Keller JC, Randolph BA, Wick DG, Michaels CM. Optimization of surface micromorphology for enhanced osteoblast responses in vitro. Int $\mathrm{J}$ Oral Maxillofac Implants. 1992; 7:302-10.

24. Martin JY, Schwartz Z, Hummert TW, Schraub DM, Simpson $\mathrm{J}$, Lankford J Jr, et al. Effect of titanium surface roughness on proliferation, differentiation, and protein synthesis of human osteoblast-like cells (MG63). J Biomed Mater Res. 1995; 29:389-401.

25. Cochran DL, Schenk RK, Lussi A, Higginbottom FL, Buser D. Bone response to unloaded and loaded titanium implants with sandblasted and acid-etched surface: A histometric study in the canine mandible. J Biomed Mater Res. 1998; 40:1-11.

26. Bornstein MM, Cionca N, Mombelli A. Systemic conditions and treatments as risks for implant therapy. Int $\mathrm{J}$ Oral Maxillofac Implants. 2009; 24: 12-27.

27. Gómez-de Diego R, Mang-de la Rosa Mdel R, Romero-Pérez MJ, Cutando-Soriano A, López-Valverde-Centeno A. Indications and contraindications of dental implants in medically compromised patients: Med Oral Patol Oral Cir Bucal. 2014; 19: e483-9.

28. Duyck J, Naert I. Failure of oral implants: aetiology, symptoms and influencing factors. Clin Oral Investig. 1998; 2: 102-14.

29. Al-Khabbaz AK, Griffin TJ, Al-Shammari KF. Assessment of pain associated with the surgical placement of dental implants. J Periodontol. 2007; 78:239-46.

30. Strbac GD, Unger E, Donner R, Bijak M, Watzek G, Zechner W. Thermal effects of a combined irrigation method during implant site drilling. A standardized in vitro study using a bovine rib model. Clin Oral Implants Res. 2014; 25: 665-74.

31. Porter JA, Von Fraunhofer JA. Success or failure of dental implants? A literature review with treatment considerations. Gen Dent. 2005; 53:423-32.

32. Salvi GE, Lang NP. Diagnostic parameters for monitoring peri-implant conditions. Int J Oral Maxillofac Implants. 2004; 19:116-27.

33. Katranji A, Misch K, Wang HL. Cortical bone thickness in dentate and edentulous human cadavers. J Periodontol 2007; 78: 874-8.

34. Misch CE. Density of bone: effect in treatment planning, surgical approach, and healing. In: Misch CE, editor. Contemporary implant dentistry. St Louis: Mosby; 1993 :469-85.

35. Meirelles L, Currie F, Jacobsson M, Albrektsson T, Wennerberg A. The effect of chemical and nanotopographical modifications on the early stages of osseointegration. Int J Oral Maxillofac Implants. 2008; 23:641-7.

36. Kim SJ, Kim MR, Rim JS, Chung SM, Shin SW. Comparison of implant stability after different implant surface treatments in dog bone. J Appl Oral Sci. 2010; 18: 415-20.
37. Ballo A, Agheli H, Lausmaa J, Thomsen P, Petronis S. Nanostructured model implants for in vivo studies: influence of well-defined nanotopography on de novo bone formation on titanium implants. Int J Nanomedicine. 2011; 6:3415-28.

38. Nandal S, Ghalaut P, Shekhawat H. A radiological evaluation of marginal bone around dental implants. An invivo study. Natl J Maxillofac Surg. 2014; 5:126-37.

39. O'Sullivan D, Sennerby L, Meredith N. Measurements comparing the initial stability of five designs of dental implants: a human cadaver study. Clin Implant Dent Relat Res. 2000; 2: 85-92.

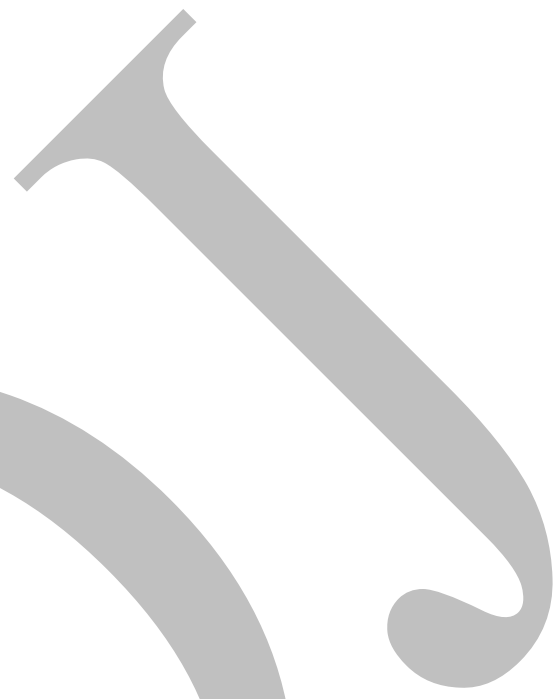

